\title{
Neonatal immune response of Brazilian beef cattle to vaccination with Clostridium botulinum toxoids types $C$ and $D$ by indirect ELISA
}

\author{
Curci VCM (1), Nogueira AHC (1), Nobrega FLC (2), Araujo RF (2), Perri SHV (3), Cardoso TC (3), \\ Dutra IS (2)
}

(1) Research and Development Unit, São Paulo Agency of Agribusiness Technology, APTA, Araçatuba, São Paulo State, Brazil; (2) Laboratory of Clostridiosis, Veterinary Medicine School, São Paulo State University (UNESP - Univ Estadual Paulista), Araçatuba, São Paulo State, Brazil; (3) Laboratory of Virology, Veterinary Medicine School, São Paulo State University (UNESP - Univ Estadual Paulista), Araçatuba, São Paulo State, Brazil.

\begin{abstract}
Types C and D strains of Clostridium botulinum are commonly related to avian and mammalian botulism. Although there are numerous vaccine recommendations, little research has been conducted to indicate the real effectiveness of vaccine timing or the ideal immunization protocol for young beef calves. Four commercially available vaccines, two bivalent (Clostridium botulinum types C and D; vaccines 1 and 2) and two polyvalent (all Clostridium spp. including Clostridium botulinum types C and D; vaccines 3 and 4), that are currently used in Brazilian herds, were tested in order to verify the maternal immune response. One hundred cows, divided into four vaccinated groups and one unvaccinated group, were given a two-dose subcutaneous immunization, at day zero, followed by a second dose given at 42 days post-vaccination, which corresponded to 40 days before birth. Serum samples $(n=75)$ were collected only from healthy neonatal calves at $0,7,45$ and 90 days post-calving (DPC) and subjected to indirect ELISA using the purified $C$ and $D$ holotoxins as capture antigens. The serological profile showed that all vaccines were able to induce a satisfactory neonatal immune response to both holotoxins at 7 DPC. However, at 45 and 90 DPC, a significant reduction $(p<0.05)$ was observed in the antibody level against $C$ and $D$ holotoxins in all tested vaccines. Neonatal immunization in calves is compromised by significant levels of maternal antibodies so that the necessity of planning a calf vaccination program involves assessment of disease risks at the production site. Finally, our findings represent the first demonstration of maternal immunity transferred to neonatal beef calves, including immunity levels after vaccination against Clostridium botulinum toxoids $C$ and D.
\end{abstract}

Key words: Clostridium botulinum, neonatal immunity, cattle, botulism, Brazil.

Bovine botulism in Brazil presents great economic and sanitary importance due to high mortality. Intoxication is caused by the ingestion of toxin $\mathrm{C}$ or $\mathrm{D}$ produced by Clostridium botulinum. In fact, the most common form of botulism in beef cattle is provoked by food or water poisoning, an important problem for sanitary programs (1-3). Probably, no area of beef calf management is filled with more questions than the development of an effective vaccine program. Antibodies from cows, transferred by colostrum, activate and regulate the innate responses present in calves to fight infection and/or help protect from intoxications (4).
In the last few years, there has been an increase in bovine vaccine production for botulism and other clostridial diseases due to the significant damage and economic losses reported by meat producers in tropical countries $(2,3,5,6)$. The market for botulism vaccines reaches approximately 45 million doses per year, and Brazil represents a potential customer due to its significant commercial livestock production. However, missing information about neonatal passive immunity and the absence of calf vaccination programs is an obstacle for epidemiological studies in extensive breeding 
areas among tropical countries. For this purpose, four commercial products (two bivalent types - C and D - and two polyvalent vaccines) were evaluated to provide maternal immunity in newborn beef calves in this study.

The maternal immune response was tested serologically by an indirect ELISA for total IgG production against $\mathrm{C}$ and $\mathrm{D}$ holotoxins. The two bivalent ( $C$ and $D$, vaccines 1 and 2 ) and two polyvalent (against all clostridial infections and also containing the two toxoids, C and D) botulism vaccines were purchased from retail stores before their expiration dates and in adequate preservation conditions. One hundred pregnant, multiparous, healthy adult Nelore cows in good general condition were clinically supervised during the entire experiment. Pathological symptoms, especially local reactions, were recorded. Cows were distributed into four groups that received vaccines (1, 2, 3 and 4$)$ and one that was not vaccinated. Vaccination was performed subcutaneously with one dose at day zero and a second dose at 42 days post-vaccination (DPV), corresponding to 40 days before the parturition. The manufacturer's instructions were followed.

Healthy nursing calves $(n=75)$ of both genders were individually identified, separated into the four groups (corresponding to their mothers vaccination schedules), and kept under the same conditions as their dams. Blood samples were collected by jugular venipuncture into serum separator tubes on day 0 and at 7, 45, 90 days post-calving (DPC). Following clot formation at room temperature, sample tubes were centrifuged at $2500 \times \mathrm{g}$ for 15 minutes, and individual serum aliquots were prepared and stored at $-20^{\circ} \mathrm{C}$.

C. botulinum toxins (types $\mathrm{C}$ and $\mathrm{D}$ ) used as capture antigen in "in house" ELISA were obtained from pure cultures at the Laboratory of Clostridioses at UNESP, Araçatuba, SP, Brazil. After conventional culture in cooked meat medium (CMM), the antigen was concentrated and purified as previously described (5). Total protein concentrations $(6.7 \mathrm{mg} / \mathrm{mL}$ for holotoxin $\mathrm{C}$ and $4.4 \mathrm{mg} / \mathrm{mL}$ for holotoxin D) were determined with the Pierce $B C A^{\oplus}$ protein assay kit (Bio-Rad, USA). Serum samples were submitted, individually and in duplicate, to indirect ELISA for detection of anti-immunoglobulin isotype $\mathrm{G}$ against $C$. botulinum toxins types $\mathrm{C}$ and $\mathrm{D}$ (7). Maxisorp ${ }^{\otimes}$ microtitration plates (Nunc, USA) were coated with $100 \mathrm{ng} /$ well of purified holotoxin in $100 \mu \mathrm{L}$ carbonate buffer $(0.05 \mathrm{M}$, pH 9.6) at $4^{\circ} \mathrm{C}$ overnight. After five washings with PBS-Tween (0.1\%) buffer, non-specific binding sites were blocked with $200 \mu \mathrm{L}$ carbonate buffer containing $15 \%$ skim milk. Five washings were followed by the addition in triplicate of $100 \mu \mathrm{L} /$ well of bovine sera diluted to 1:200 for holotoxin type C and to $1: 400$ for holotoxin type $\mathrm{D}$, and samples were incubated for two hours at $37^{\circ} \mathrm{C}$ in a humidified chamber. The optimal serum dilution was determined beforehand by serial dilutions. For background controls no serum was added.

After a further washing step, $200 \mu \mathrm{L}$ of peroxidase-labeled rabbit anti-bovine $\operatorname{IgG}$ antibody $(1: 20,000)$ (Sigma-Aldrich Corp., USA) diluted in PBS-Tween (0.1\%) was added to the corresponding wells, and plates were kept for two hours at $37^{\circ} \mathrm{C}$. Enzymatic activity was shown by addition of $200 \mu \mathrm{L} /$ well orthophenylene-diamine substrate $(0.4 \mathrm{mg} / \mathrm{mL})$ in citrate buffer $(0.05 \mathrm{M}$, $\mathrm{pH}$ 5) containing $0.06 \%$ hydrogen peroxidase. Absorbance values were immediately read at 492 $\mathrm{nm}$ in a microplate reader (Thermo Labsystems, USA). Results are expressed as the optical density (OD) above background controls.

For the evaluation and comparison of maternal immune response against $C$. botulinum $\mathrm{C}$ and $\mathrm{D}$ toxin types in neonatal calves, respective values were transformed in $\log (\mathrm{x}+1)$ and submitted to repeated measures analysis of variance. Means were compared by Tukey's test, and differences were considered to be significant when $\mathrm{p}<0.05$. Statistical analysis was carried out using SAS $^{\odot}$ software (8).

The mean values of ODs calculated from neonatal calf sera are illustrated in Figure 1. The maternal immune responses against holotoxins $\mathrm{C}$ and $\mathrm{D}$ produced by $C$. botulinum type $\mathrm{C}$ at 7 DPC were higher and similar in all studied groups ( $p>0.05$ ). However, at $45 \mathrm{DPC}$, the immune responses corresponding to bivalent and polyvalent vaccines (vaccines 1 and 4) were significantly superior to those corresponding to the two other products (vaccines 3 and 2) for type $\mathrm{C}$ holotoxin. All vaccinated animals showed a significant decrease in immune response at 45 DPC (Figure 1 - A and B). The neonatal passive response to holotoxin $\mathrm{D}$ was considerably higher than to holotoxin $\mathrm{C}$ at $45 \mathrm{DPC}$, as displayed in Figure $1-\mathrm{B}$. However, at 90 DPC, the neonatal passive responses among all vaccinated animals showed no differences. 

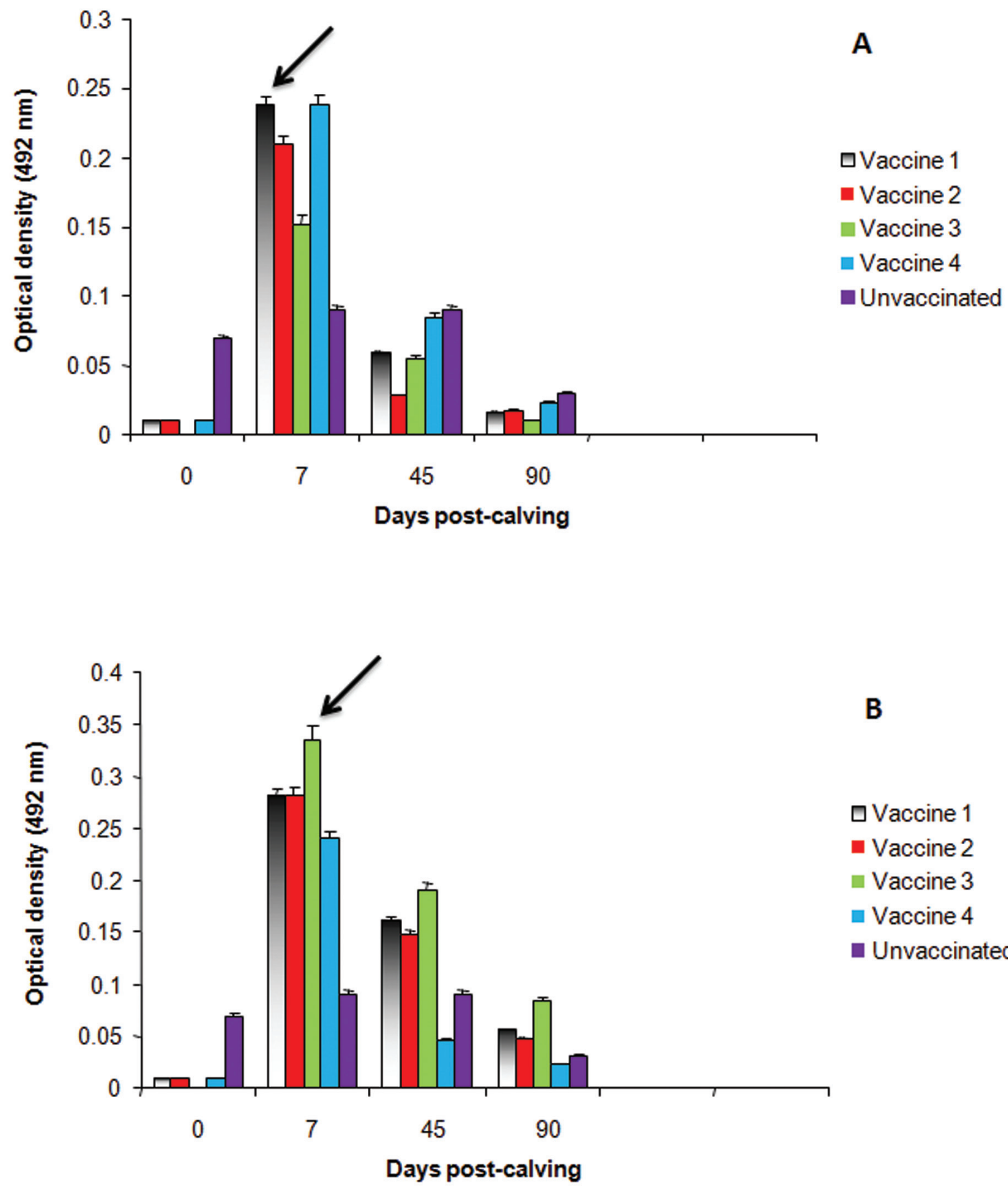

B

๑ Vaccine 1

- Vaccine 2

- Vaccine 3

- Vaccine 4

Unvaccinated

Figure 1. Neonatal passive immune response from beef calves obtained from vaccinated pregnant cows against Clostridium botulinum toxoids $C$ and $D$ with four commercial vaccines (vaccines 1, 2, 3, and 4), measured by indirect ELISA using (A) holotoxins $C$ and (B) D as capture antigens. Standard deviations were below $5 \%$ of mean values of four independent measurements and are shown in the figure. Highest antibody levels are shown by arrow. 
Development of vaccines for botulism and other clostridial diseases has been an active area of research. Antibodies from cows, transferred by colostrum, activate and regulate the innate responses present in calves. This passive immunity is a double-edged sword for young calves: protection from disease on one side, and interference with calf's ability to develop immunity to vaccine antigen on the other (4). Newborn calves are immunologically naive at birth. They have had no chance to enhance adaptive immunity by "experience" because of the protective environment in the womb, which also limits the activation of phagocytes and their entry into the tissues. So, antibody is a critical component of colostrum and provides an immediate source of antibody for agammaglobulinemic calves. Numerous studies report the efficacy of neonatal vaccination in dairy calves, including virus and bacterial antigens; however, none of them has demonstrated the neonatal immune response of beef calves until now (9).

With respect to the passive neonatal immune response directed against holotoxins types $\mathrm{C}$ and $\mathrm{D}$ in this trial, vaccine $1(\mathrm{C})$ showed more efficiency than vaccine 2(D) at 7 and 45 DPC than at any other time. In addition, after 45 days after vaccination, the neonatal immune response was considered lower and probably inadequate for holotoxin C, but was better for type D. Despite many reports using the mouse protection assay, IgG titers from indirect ELISA performed in this study were sufficient to analyze the neonatal immune response during post-calving periods (10).

In fact, different immunization protocols have been evaluated by previous studies, and most of them demonstrated that maternal antibody, or antibody acquired by the calf from absorption of colostral antibody during the first 24 to 48 hours after birth, has a profound suppressive effect on active immunization of most vaccines $(6,11)$. However, the period during which the colostral-acquired antibody interferes with active immunization depends on the amount of colostrum absorbed. Studies conducted to evaluate the efficiency of infectious bovine rhinotracheitis, bovine viral diarrhea, parainfluenza and respiratory syncytial virus vaccines, have demonstrated that 30 days following primary vaccination of beef calves (at 28 days of age), mean antibody levels to all viruses had declined (11). This means that maternal antibodies have an important interference on active neonatal immunity at early stages of calf life. The reason for better immune response to holotoxin $\mathrm{D}$ than to holotoxin $\mathrm{C}$ is not completely understood. Biochemical properties, antigen concentration and adjuvant may explain this difference, but these points were not addressed in this study. One reasonable explanation for the increased titer in unvaccinated group at days 7 and 45 is the field challenge. In spite of this, bovine sera have a tendency to react with matrix of immunoplates (6).

Multistrain Clostridium spp. bacterin-toxoids are a frequent part of vaccination programs of heifers. In spite of many studies that indicate local reactions following vaccination as a negative point to North American meat producers, in this study no reactions were observed (11). In addition, maternal antibody interference significantly inhibited Clostridia spp. antibody responses (1214). Based on the present findings, at least regarding Clostridium botulinum, active immunization is recommended until $45 \mathrm{DPC}$, due to the high level of neonatal immune response acquired by colostrum from vaccinated dams. Finally, the success of a vaccination programs depends on management, adequate timing of vaccination and the proper use of the commercial product.

\section{COPYRIGHT}

(C) CEVAP 2010

\section{SUBMISSION STATUS}

Received: January 13, 2010.

Accepted: March 26, 2010.

Abstract published online: March 26, 2010.

Full paper published online: August 31, 2010.

\section{CONFLICTS OF INTEREST}

There is no conflict.

\section{FINANCIAL SOURCE}

CNPq and FAPESP.

\section{ETHICS COMMITTEE APPROVAL}

All animal handling and sample collection procedures were performed in accordance with the recommendations of the Brazilian Society of Laboratory Animal Science (SBCAL/COBEA), and all experiments were approved by the Ethics and Animal Welfare Committee (2008/006789). 


\section{CORRESPONDENCE TO}

VERA CLÁUdIA MAGALHÃES CURCI, Unidade de Pesquisa e Desenvolvimento de Araçatuba, Agência Paulista de Tecnologia dos Agronegócios, APTA, Av. Alcides Fagundes Chagas, 122, Araçatuba, São Paulo, SP, 15.055240, Brazil. Email: vlmcurci@apta.sp.gov.br.

\section{REFERENCES}

1. Baldassi L. Clostridial toxins: potent poisons, potent medicines. J Venom Anim Toxins incl Trop Dis. 2005;11(4):391-411.

2. Ortolani EL, Brito LA, Mori CS, Schalch U, Pacheco J, Baldacci L. Botulism outbreak associated with poultry litter consumption in three Brazilian cattle herd. Vet Hum Toxicol. 1997;39(2):89-92.

3. Dutra IS, Döbereiner J, Rosa IV, Souza LAA, Nonato M. Surtos de botulismo em bovinos no Brasil associados à ingestão de água contaminada. Pesq Vet Bras. 2001; 21(2):43-8.

4. Chase CC, Hurley DJ, Reber AJ. Neonatal immune development in the calf and its impact on vaccine response. Vet Clin North Am Food Anim Pract. 2008;24(1):87-104.

5. Steinman A, Chaffer M, Elad D, Shpigel N. Quantitative analysis of levels of serum immunoglobulin G against botulinum neurotoxin type $\mathrm{D}$ and association with protection in natural outbreaks of cattle botulism. Clin Vaccine Immunol. 2006;13(8):862-8.

6. Steinman A, Galon N, Arazi A, Bar-Giora Y, Shpigel NY. Cattle immune response to botulinum type
D toxoid: results of a vaccination study. Vaccine. 2007;25(44):7636-40.

7. Stahl C, Unger L, Mazuet C, Popoff M, Straub $\mathrm{R}$, Frey J. Immune response of horses to vaccination with the recombinant $\mathrm{Hc}$ domain of botulinum neurotoxin types $\mathrm{C}$ and $\mathrm{D}$. Vaccine. 2009;27(41):5661-6.

8. SAS Institute Inc. SAS OnlineDoc ${ }^{\oplus}$, Version 8. Cary: SAS Institute Inc; 1999.

9. Firth MA, Shewen PE, Hodgins DC. Passive and active components of neonatal innate immune defenses. Animal Health Res Rev. 2005;6(2):14358.

10. Gregory AR, Ellis TM, Jubb TF, Nickels RJ, Cousins DV. Use of enzyme-linked immunoassays for antibody to types $\mathrm{C}$ and $\mathrm{D}$ botulinum toxins for investigations of botulism in cattle. Aust Vet J. 1996;73(2):55-61.

11.Troxel TR, Gadberry MS, Wallace WT, Kreider DL, Shockey JD, Colburn EA, et al. Clostridial antibody response from injection-site lesions in beef cattle, long-term response to single or multiple doses, and response in newborn beef calves. J Anim Sci. 2001;79(10):2558-64.

12. Morein B, Abusugra I, Blomqvist G. Immunity in neonates. Vet Immunol Immunopathol. 2002;87(3-4):207-13.

13. Cheng LW, Stanker LH, Henderson II TD, Lou J, Marks JD. Antibody protection against botulinum neurotoxin intoxication in mice. Infect Immun. 2009;77(10):4305-13.

14. Smith LA. Botulism and vaccines for its prevention. Vaccine. 2009;27(Suppl 4):33-9. 